\title{
10. IAȘI ART RESIDENCY INTERNATIONAL ARTIST RESIDENCY PROGRAM. AMERICAN ARTIST-IN-RESIDENCE JOHN DILLARD
}

\author{
Ioana Palamar ${ }^{241}$
}

\begin{abstract}
Iași Art Residency is an artistic residency program that takes place in Iasi and involves the monthly invitation of an international visual artist, in order to materialize a specific art project related to the experience lived in the cultural space of Iasi. The program aims to connect the students of the Faculty of Visual Arts and Design within "George Enescu" National University of Arts in Iași with the invited artists, in order to exchange artistic experiences. This article will briefly present the activity of the American resident artist John Dillard whuch took place here, in Iasi, in January and February 2019.
\end{abstract}

Key words: residency, international, collaboration, culture, art

\section{Introduction}

Iași Art Residency international cultural program is based on connections between different cultures by organizing specific art activities in the art educational field (like: art exhibitions, debates, workshops, etc.). Students from the Faculty of Visual Arts and Design within George Enescu National University of Arts from Iasi, especially those from Painting Department, are the target group of this program that is invited to regularly get in touch with young international artists guests. They are graduates of famous art academies and are at the beginning of their artistic career, but they also have a certain artistic experience that they are able to share with the others. The project is already part of the international network of residency programs called Res Artists. ${ }^{242}$ The short-term objectives of this art residency project are:

1. Immediate learning of new (painting, graphics, etc.) techniques, respectively of new artistic languages (such as: performance, video art, etc.) 2. Educating the students's taste in the visual arts field by helping them getting accustomed to: new practices, experiences, arts events, with the international art market, ways of promoting art, the hierarchical system: artist-gallery-curatordealer, etc.

The main long-term objective of this art residency project is to foster a possible future collaboration between our students and the invited artists-in-residence, materialized by:

1. Organization of international solo or group exhibitions;

2. Participation in various art projects, art festivals, international art biennials;

3. Promoting, on an international level, one's own works and art projects;

4. Getting in touch with international art galleries;

\footnotetext{
241 Assistante PhD., "George Enescu" National University of Arts from Iaşi, Romania, email: ioanapalamar@yahoo.com

${ }^{242}$ Iasi Art Residency, I.A.R., https://resartis.org/listings/artalpha/ (30.10.2020), Ioana Palamar, About artists, http://www.ioanapalamar.com/iasi-art-residency/\#undefined3 (30.10.2020)
} 
5. Promotion of the Faculty of Visual Arts and Design from Iași;

6. Promoting the cultural space of Iași.

\section{Discussions}

The artists' residency period extends from 4 to 5 weeks, at the end of which the artists-in-residence will present their art project by:

1. Organizing a solo exhibition either at Aparte Gallery of the Faculty of Visual Arts and Design, or at another local gallery;

2. Organizing an open talk with the students and teachers of this institution, as well as with local artists and art lovers, at Mihai Ursachi House of Culture in Iași or in another local institution;

3. Donation of one artwork done during the residency period.

A particularly important aspect, which coagulates this international artist residency program, consists in creating a bridge between different cultures by sharing artistic and cultural experiences, as well as by promoting the cultural scene from Iasi, our Faculty of Visual Arts and Design from Iasi and especially the Painting Department. Iași Art Residency program is aimed at young international artists interested in the Romanian cultural space, especially in the visual art field from Iași, as well as in collaboration with the students of the Faculty of Visual Arts and Design from Iași, but also with local artists.

The main factors that contribute to the success of this cultural project are a good organization and a fruitful intercultural exchange. Project members: Associate Professor PhD. Zamfira Bîrzu, Associate Professor PhD. Cristian Ungureanu, Assistante PhD. Andrei Pantea, Art critic Maria Bilașevschi, students volunteers: Cezara Moraru, Laura Pricope, Laura Andreea Dascălu, Cristiana Aniță, Victoria Cucoranu, Karina Cojocaru and Smaranda Vîrnă. Project Coordinator: Assistante PhD. Ioana Palamar.

\section{Solo exhibition, American artist-in-residence John Dillard}

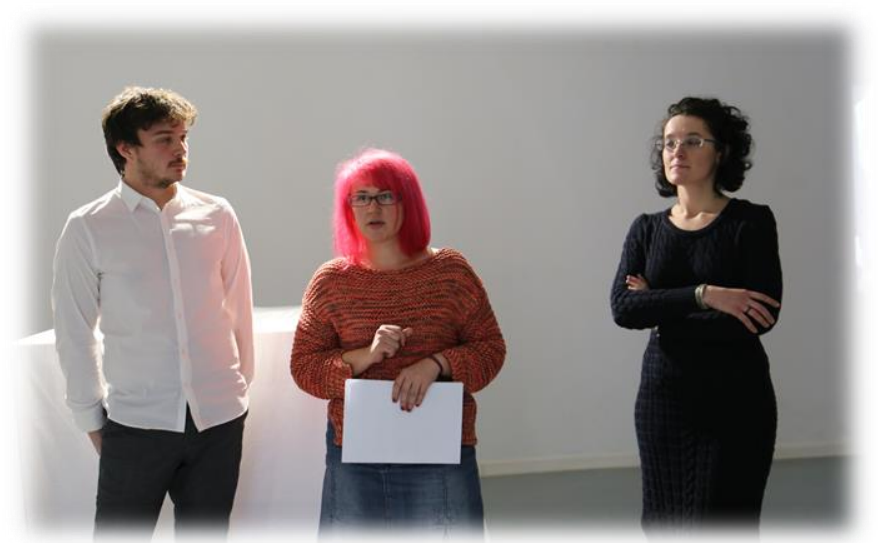

Fig. 1 John Dillard, SUA, Da, mulțumesc solo multimedia exhibition, Aparte Gallery, Faculty of Visual Arts and Design, Iași, 07.01 - 10.02.2019

The American artist-in-residence John Dillard's multi-media solo exhibition (see figure no.1) took place at Aparte Art Gallery of the Faculty of Visual Arts and Design from Iași, on $5^{\text {th }}$ of February 2019. The artistic event had an eclectic characteristic consisting of a performance, a video installation and an installation 
entitled Meta (see figure no. 2), accompanied by several conceptual sculptures.

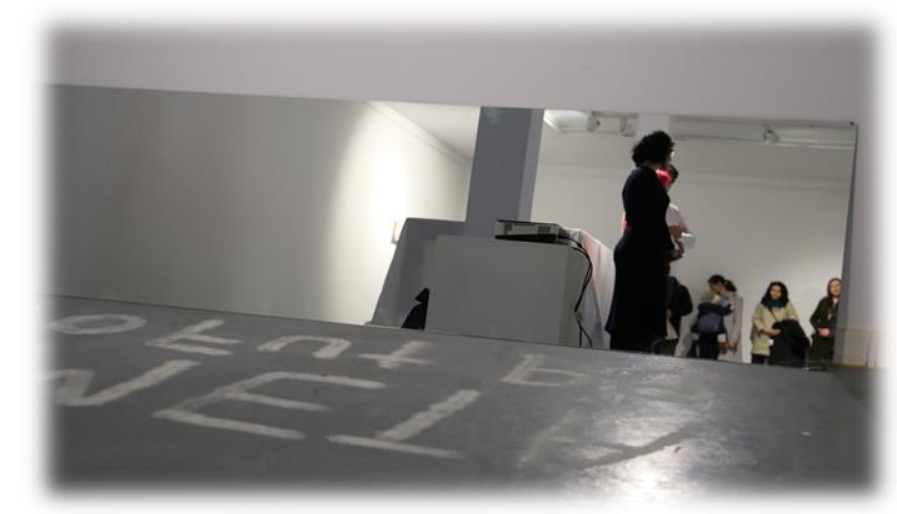

Fig. 2 John Dillard, SUA, Da, mulțumesc solo multimedia exhibition, Aparte Gallery, Faculty of Visual Arts and Design, Iași, 07.01 - 10.02.2019

The performance, the main motif of this exhibition, becomes a symbol of the artist's attempt to connect to a totally different culture, it becomes a visual translation of a moral attempt to new existential parameters. The students involved in this performance created a symbolic cordless telephone, a row that forms a unitary whole. Basically, this performance is composed of two human segments: the group that personifies a new cultural element and the artist that personifies the intrusive human factor that intends to integrate culturally in a different environment, in order to create a relationship with it.

Here I would like to come with an additional explanation, in the sense that I want to make reference to the continued and intermediate fractions, as well as to their relationship, an issue addressed by some professors from the University of Belgrade, Faculty of Electronic Engineering, namely: Luka Milinkovic, Branko Malesevic and Bojan Banjac ${ }^{243}$ who mathematically demonstrate the theory of these two types of fractions studied in the last two centuries, highlighting the fact that there is such a continuity with scientific application ${ }^{244}$. Basically, they are looking for a solution to highlight the idea of connection that brings together different types of fragments. I made this parallel between two totally different fields of activity in order to highlight, through a relationship from an objective vs. subjective point of view, this attempt of connection and integration represented, in this case, through the performative language (see figures no. 3, 4).

This action art shows in fact a culinary act, a symbol of a new information whose essence is gradually lost during the crossing directed towards the artist who manages to capture only a part of the food, which symbolises the essence of a new culture. Basically, he feeds physically and metaphorically speaking, with vestiges of food / information that cause him a feeling of frustration and inability to a total harmonization in a completely different environment. Basically, language is considered to be a human capacity for complex communication, with an identity value specific to a certain community ${ }^{245}$ which is a little difficult to access. Therefore, these two human segments are, in fact, two structural elements that tend

\footnotetext{
${ }^{243}$ Luka Milinkovic, Branko Malesevic and Bojan Banjac, Continued fractions, intermediate fractions and their relation to the best approximations, in „Journal of Science and Arts”, no. 3 (52), pp. 545-560, 2020

${ }^{244}$ Idem, p.559

${ }^{245}$ Culture and adaptation, https://courses.lumenlearning.com/boundless-sociology/chapter/culture-and-adaptation/ $(30.10 .2020)$
} 
to metamorphose into relational elements, in their emerging attempt at selftranscendence. However, the success is only partial due to the cultural conditioning that doesn't totally discourage the artist, who continues to make efforts to survive in a foreign space.
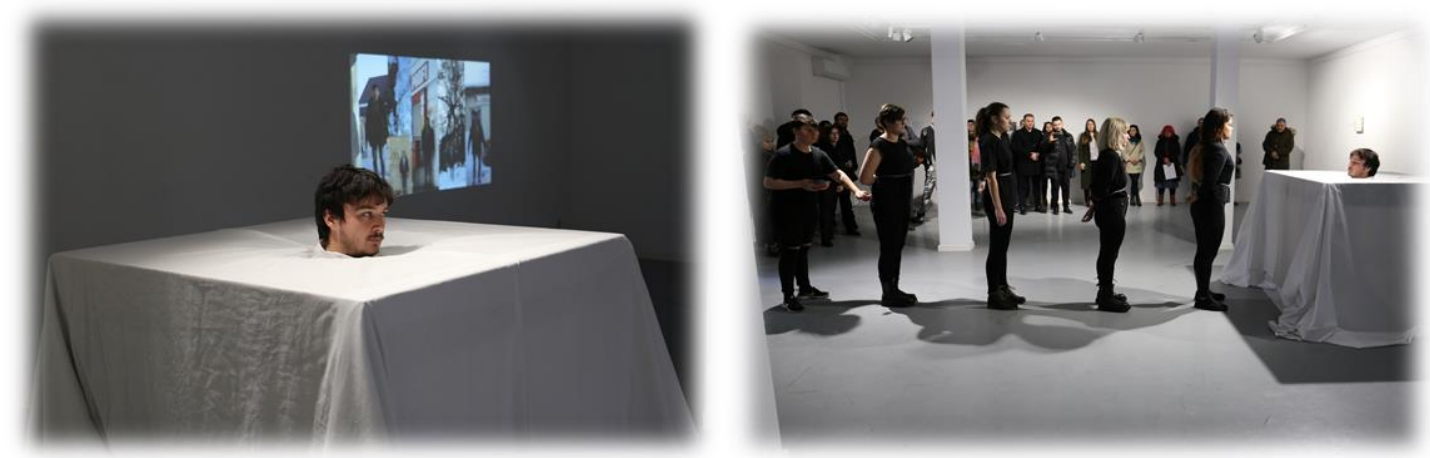

Fig. 3, 4 John Dillard, SUA, Da, mulțumesc solo multimedia exhibition, performance, Aparte

Gallery, Faculty of Visual Arts and Design, Iași, $07.01-10.02 .2019$

The conceptual sculptures (see figures no. 5 and 6) are installations, being made up of simple utilitarian objects that become the expression of his cry to adapt. As the art critic Maria Bilașevschi remarked, the artist tears the canvas not in a gesture of masculinity, but in order to overcome the rigidity of the canvas and to step through form and its shadow outside the box, whether this action is literally a physical or a psychological one. ${ }^{246}$
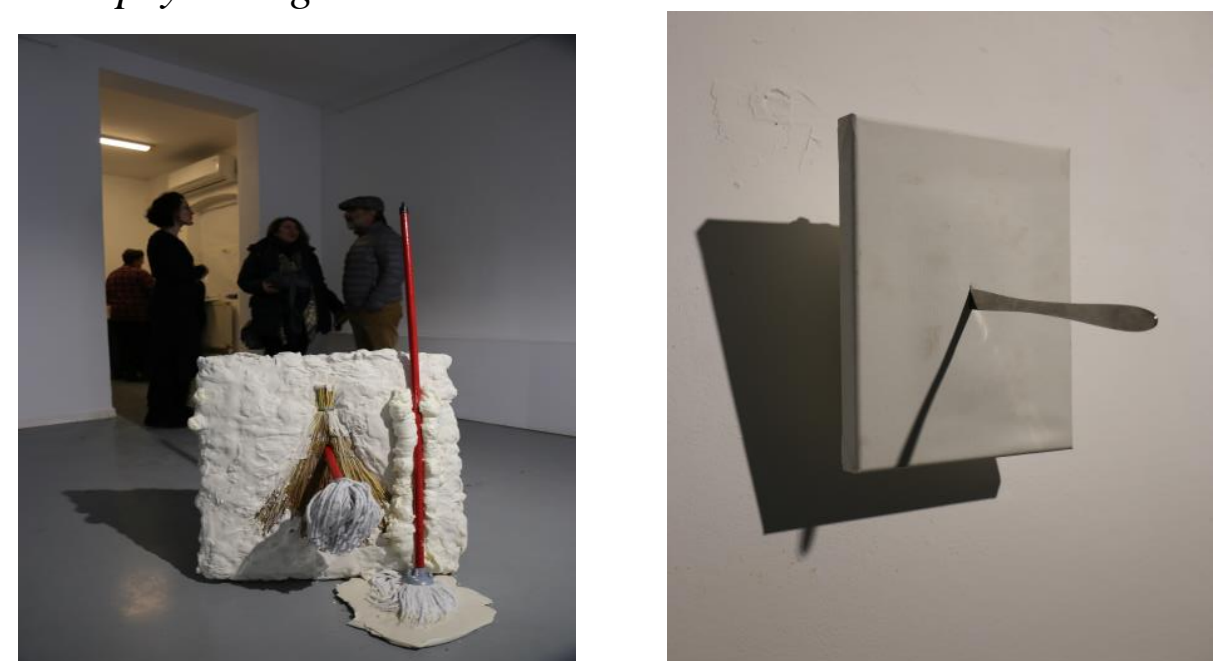

Fig. 5, 6 John Dillard, SUA, Da, mulțumesc solo multimedia exhibition, conceptual sculptures, Aparte Gallery, Faculty of Visual Arts and Design, Iași, 07.01 - 10.02.2019

His effort to adapt to a new cultural environment is very clearly explained by the artist himself through his artistic creation that includes groups of usual, utilitarian and sculptural installations: My work centers around the idea of sculpture as object; more importantly the intersection between objects and sculptures. I'm looking for slippage between the two and how we as artist communicate that difference. Mining the vibrating gap between these two things to create my work. I'm often questioning object fixedness, sense of purpose and utility. I create sculptural forms that reference these objects visually. Communities of objects: dishes, furniture, and documents are some of the things in which I am

\footnotetext{
${ }^{246}$ Maria Bilașevschi, art critic, statement regarding the American artist-in-residence's exhibition Da, mulțumesc, which took place at Aparte Gallery within the Faculty of Visual Arts and Design from Iași, in the period 07.01 10.02.2019
} 
most intrigued by. An object whose sense of purpose belongs to a familiar group is even more complex. A sense of belonging to a greater collective is a desire that manifests in my studio. Many of my sculptures are presented in groups for this reason. These groups often reference singular moments over a particular period of time, personified as an object. The display of these collective moments is at the core of my work now.

\section{Conclusions}

This artist residency program creates such socio-cultural situations that problematize the concept of culture and identity within the educational framework, by challenging students to perceive and relate to new cultural and human dimensions.

\section{Article}

\section{References}

1. Milinkovic Luka, Branko Malesevic și Bojan Banjac, 2020, Continued fractions, intermediate fractions and their relation to the best approximations in „Journal of Science and Arts”, no. 3 (52), 24.03.2020, pp. 545-560, online publication

\section{Web sites}

1. Culture and adaptation, https://courses.lumenlearning.com/boundlesssociology/chapter/culture-and-adaptation/ (30.10.2020)

2. Iaşi Art Residency, I.A.R., https://resartis.org/listings/artalpha/ (30.10.2020)

3. Ioana Palamar. About artists, http://www.ioanapalamar.com/iasi-artresidency/\#undefined3 (30.10.2020)

4. Journal of Science and Arts, http://www.josa.ro/en/index.html?http\%3A//www.josa.ro/en/josa.html (30.10.2020) 